\title{
The significance of the number seven in ancient Greece and its relation to Endocrinology
}

\section{Menalaos L. Batrinos}

\section{Athens, University School of medicine Athens, Greece}

Many ancients held various beliefs about the supernatural virtues of certain numbers. In ancient Greece, the school of Pythagoras (590 BC) taught the doctrine of the numerical essence of natural events. In accordance with this theory, the number 7 was considered a sacred number and thus vital to human life.

Solon (640-560 BC), one of the "seven sages" of Greek antiquity, was the first to notice that certain biological events lend themselves to numerical description and divided the ages of man into ten, each lasting seven years.

Hippocrates (640-370 BC), divided man's life span into multiples of 7 . Thus, according to him, one is a child up to the age of 7 "during which period the emergence of the teeth is completed", a boy until the age of $14(7 \times 2)$ at which time "the sperm is produced", a youth until the age of $21(7 \times 3)$ when "the thickness of the beard is completed", a young man until the age of $28(7 \times 4)$, a man up to the age of $49(7 \times 7)$, a "presbyter" or elder until the age of $56(7 \times 8)$ and then on up to the age of $7 \times 14$ (98 years) an old man.

Aristotle (384-323 BC) states that the menarche occurs at "around the age of two times seven" (14 years) and the age of $21(7 \times 3)$ is the optimum age for childbearing. The age of menopause is indirectly mentioned by him in his writings to be the $50^{\text {th }}$ year $(7 \times 7$ rounded to 50) since he states that "for the most part, 50 marks in women the end of births".

Reflecting upon these ancient observations, one is tempted to remark that in both sexes, certain endocrine events also occur at chronological ages that are multiples of seven" adrenarche occurs at about the $7^{\text {th }}$ year of age and menarche and sperm production close to the age of $14(7 \times 2)$. By the age of 21 years $(7 \times 3)$ the ortimum bone mass has been acquired and a pregnancy by this age protects from breast cancer. At about the age of $28(7 \times 4)$, the decline of growth hormone production begins, which thence falls by $50 \%$ every 7 years. At the age of $35(7 \times 5)$, a progressive decline in adrenal androgen production commences together with a steep diminution of ovarian follicles. The age of $42(7 \times 6)$ is believed to mark the beginning of the premenopausal period and the age of $49(7 \times 7)$ is the average age of menopause.

Should an endocrinologist in our modern era of evidence-based medicine be attracted by the mystic virtues of numbers, he/she is welcome to discover what other endocrine changes or other biological phenomena have connections with the number 7 . 
First response to the invitation by ML Batrinos with regard to number 7 from the Editor in Chief: motif are characterized by the presence of the aminoacid leucine at every seventh aminoacid (Figure 1).

The transcription factors with the leucine zipper

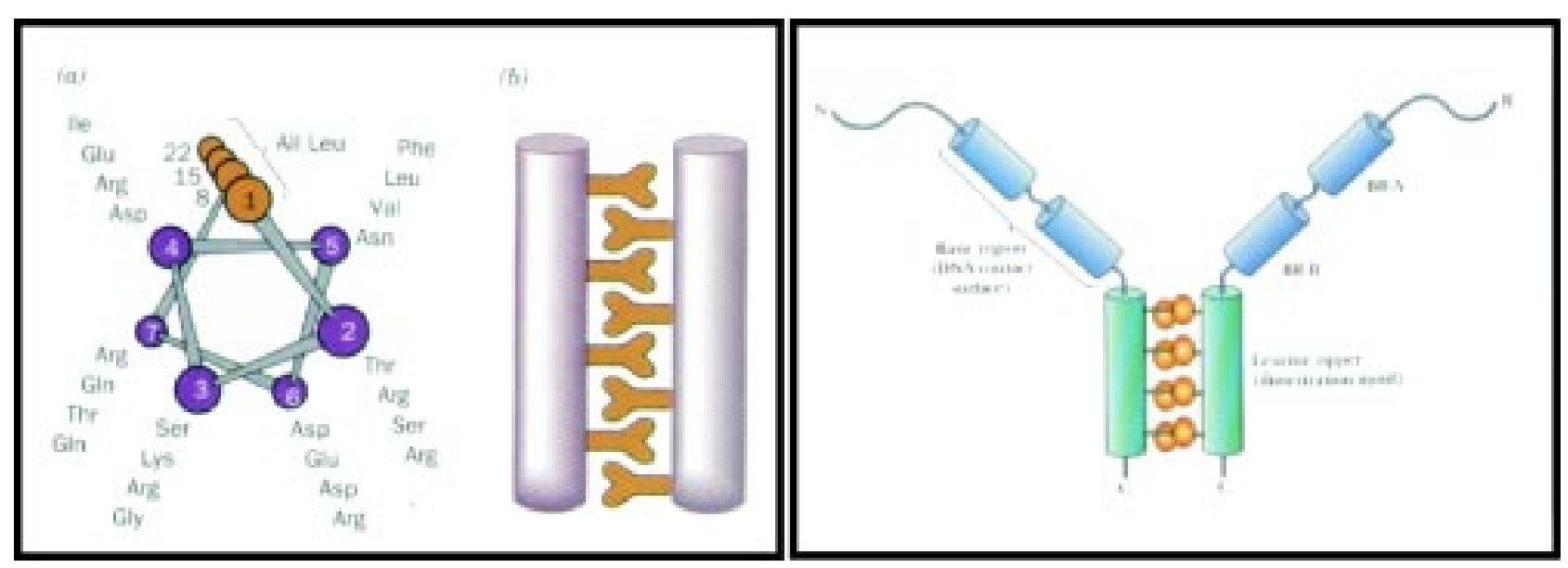

Figure 1. 